NASA Technical Memorandum 81890

\author{
NASA-TM-81890 19800025270
}

\title{
MULTI-PARAMETER YIELD ZONE MODEL FOR \\ PREDICTING SPECTRUM CRACK GROWTH
}

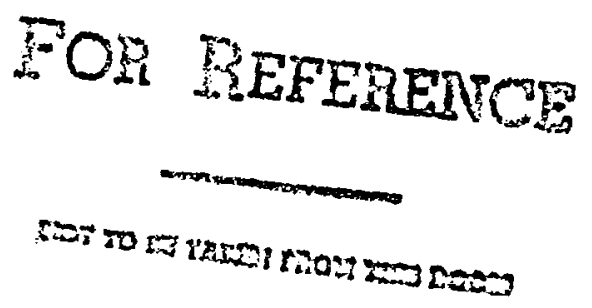

W. S, Johnson

SEPTEMBER 1980

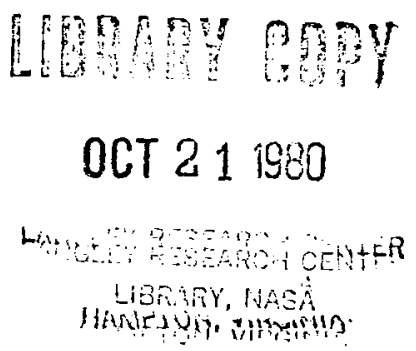

\section{NRS \\ National Aeronautics and Space Administration




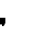


MULTI-PARAMETER YIELD ZONE MODEL FOR

PREDICTING SPECTRUM CRACK GROWTH

\author{
W. S. Johnson \\ NASA Langley Research Center \\ Hampton, Virginia 23665
}

\begin{abstract}
A systematic technique is presented for modeling crack growth load interaction effects due to spectrum loading. The Multi-Parameter Yield Zone (MPYZ) model accounts for crack growth retardation, acceleration, and underload effects. The load interactions are attributed to the residual stress intensity due to the plastic deformation at the crack tip. As part of an ASTM E24.06.01 round-robin effort, fatigue crack growth was predicted and compared with test data for a variety of spectrum loadings.
\end{abstract}

\title{
LIST OF SYMBOLS
}

A ratio of $\mathrm{K}_{\max }^{\mathrm{OL}} / \mathrm{K}_{\max }$ above which no retardation occurs

a half surface crack length, $m$

$a_{\text {ap }} \quad$ half crack length when current stress applied

$a_{f} \quad$ final half crack length of crack growth prediction

$a_{i} \quad$ initial half crack length of crack growth prediction

$a_{\text {OL }} \quad$ half crack length when overload applied

B ratio of $\mathrm{K}_{\max }^{\mathrm{OL}} / \mathrm{K}_{\max }$ for single overload below which no crack growth occurs

$B^{\prime} \quad$ ratio of $\mathrm{K}_{\max }^{\mathrm{OL}} / \mathrm{K}_{\max }$ for any number of overloads below which no crack growth occurs 


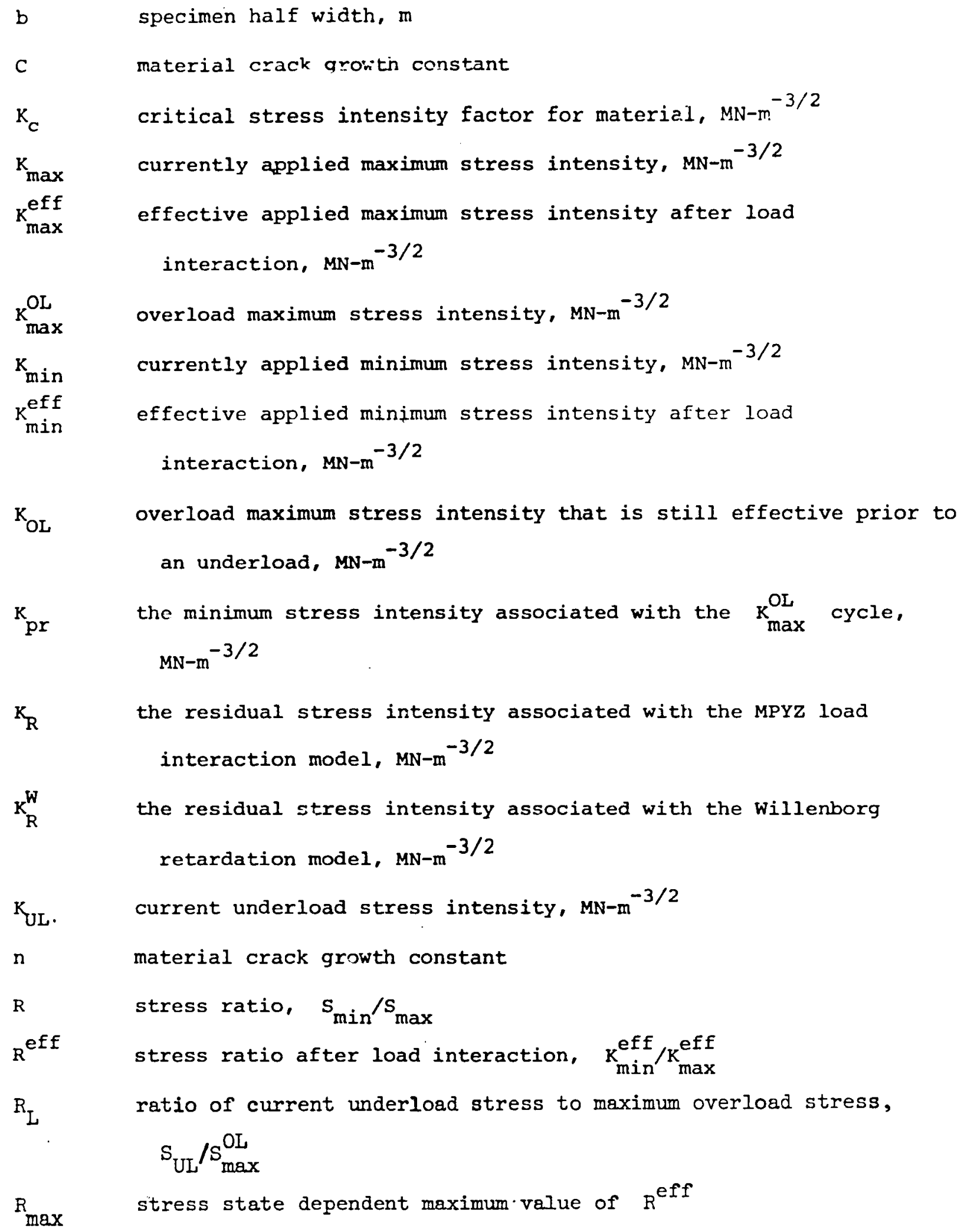




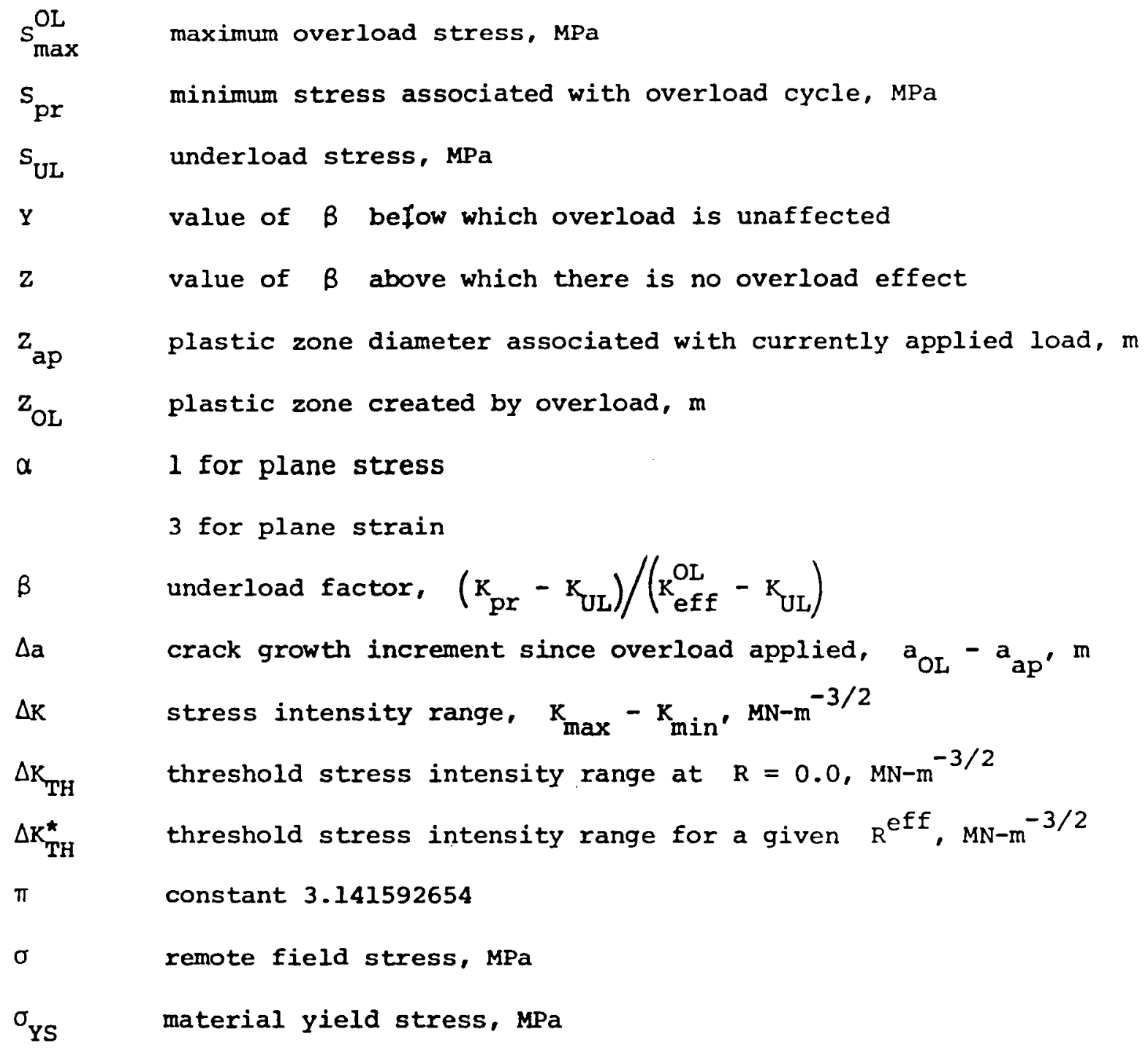


be experimentally determined for each condition of material, loading, and environment that is of interest. The willenborg model, on the other hand, does not incorporate an empirical shape factor but uses the material yield stress to give a plastic zone size, which is then used to calculate crack retardation. Although the willenborg model does not incorporate a "fudge" factor, its predictions are not always satisfactory. The Elber model is based on the crack-closure phenomenon and uses an effective stress intensity which is based upon the stress needed to open the crack. The closure factor in the Elber model is determined experimentally from constantamplitude data. The Elber model has been used in the aerospace community with limited success. These models have been modified by various investigators during the past five years with some degree of success [4-7].

Recent testing at General Dynamics [8-9], as well as work performed by Hillberry [10-12] and others [13-14], have shown that various loading parameters that are not included in the Wheeler or Willenborg models (such as crack growth acceleration and underloads) have a significant effect on spectrum crack growth.

This paper will present a phenomenological load interaction model referred to as the Multi-Parameter Yield Zone (MPYZ) load interaction model. It is a subprogram within the computerized crack growth program CGR in references 15 and 16. The crack growth model is discussed first, followed by the load interaction model. The load interaction model is described in three sections: retardation, acceleration, and underload effects. The crack growth predictions are discussed and compared with the experimental results. The present'study was part of a round-robin effort that was sponsored by ASTM Subcommittee E24.06. The purpose of this round-robin effort was to 
compare various methods for predicting crack growth through center cracks in 2219-T851 aluminum alloy center-crack tension specimens subjected to aircrafttype spectrum loadings. The data used for the round robin were generated by Chang and Stolpestad [17] under an Air Force sponsored contract. AlI material data in this paper can be found in reference 17, except as noted.

CRACK GROWTH MODEL

Numerous fatigue crack propagation models have been proposed in the literature to describe the relationship between the crack growth rate, da/dN, and the stress intensity range, $\Delta \mathrm{K}$. Many of these relationships consider such parameter as stress ratio, $R$, and fracture toughness, $K_{c}$. Gallagher [Gallagher, J. P., "Fatigue Crack Growth Rate Laws Accounting for Stress Ratio Effects," ASTM Task Force E24.04.04, Report No. 1, 1974.] has summarized a number of these models.

The Forman [24] crack growth model provides a good fit for the constant amplitude 2219-T851 aluminum crack growth data furnished for the spectrum crack growth prediction round-robin. For the present study, the Forman equation was slightly altered to the following form:

$$
\mathrm{da} / \mathrm{dN}=\frac{\mathrm{C} \Delta \mathrm{K}^{\mathrm{n}}}{\left(1-\mathrm{R}^{\mathrm{eff}}\right)^{\mathrm{m}} \mathrm{K}_{\mathrm{C}}-\Delta \mathrm{K}}
$$

where

$$
\begin{array}{ll}
\mathrm{m}=1 & \text { at } \\
\mathrm{m}=2 & \text { at } \mathrm{R}<0
\end{array}
$$

The equation is exactly that suggested by Forman except for the exponent applied to the stress ratio. The exponent $m=2.0$ for negative $R^{\text {eff }}$ values. Equation (1) accounts for the crack growth behavior 
by using the full stress intensity range, $\Delta K$, and the corresponding $R^{\text {eff }}$ values, i.e., the stress range includes compressive portions. Load interaction effects are accounted for by adjusting $R^{\text {eff }}$ during each cycle, so $R^{\text {eff }}$ does not necessarily equal the actual stress ratio of the current cycle. Most of the present paper is about the procedure used to find the proper values of $R^{\text {eff }}$ to account for retardation, acceleration, and underload effects. The parameters $c$ and $n$ were found from the supplied constant amplitude crack growth data [17] by a least-squares regression analysis. The critical stress intensity factor, $K_{C}$, was chosen to be $88 \mathrm{MN}-\mathrm{m}^{-3 / 2}$ (80 ksi $\sqrt{\mathrm{in}}$ ), which resulted in $\mathrm{C}=3.68 \times 10^{9}$ and $\mathrm{n}=3.232$. The author has formulated an opinion from observed crack growth behavior, and from crack closure considerations of Newman [19], that the maximum effective stress ratio is a function of the constraint at the crack tip due to the different stress states, i.e., plane-stress or plane-strain or in between. Therefore a simple relationship has been used to determine the maximum allowable stress ratio used in equation (1):

$$
R_{\max }=[z / t \times 0.2]+0.6
$$

where $z=\frac{1}{\alpha \pi}\left(\frac{K_{\max }}{\sigma_{y}}\right)^{2}$ is the plastic zone diameter for the applied $K_{\max }$ $t$ is the material thickness, and $\alpha$ is 1.0 or 3.0 for plane stress or strain assumption, respectively. Notice that for plane-strain $(z / t \rightarrow 0)$ so that $R_{\max }=0.6$. Therefore if an applied cycle had a stress ratio equel to 0.75 , but was cycled in a plane-strain region, a value of approximately 0.6 would be used in equation (1) for $R^{\text {eff }}$. If the plastic zone diameter 
equals or exceeds the thickness, then a state of plane-stress is assumed, and $R_{\max }=0.8$, i.e., maximum value for $R^{\text {eff }}$ in equation (1) is 0.8 .

Figure 1 depicts the fit of equation (1) to the data. The solid line represents perfect correlation while the dashed lines represent a factor of two discrepancy. The constant amplitude data consisted of $R$ values between -1.0 and 0.7 and maximum stress levels from 55.2 to $276 \mathrm{MPa}$. Figure 1 is a plot of the predicted crack growth rates versus the actual growth data used to evaluate the $\mathrm{C}$ and $\mathrm{n}$ in equation (1). Several constant amplitude tests at $276 \mathrm{MPa}$ (40 ksi) were not included because of net section yielding; the author did not want to bias the crack growth equation for this extreme case. It is interesting to note that equation (1) does a good job of correlating the negative and positive stress ratios.

Typically, many cycles in a variable-amplitude loading program produce stress intensity ranges, $\Delta K$ !s, that are so small no crack growth results. The threshold stress intensity range, $\Delta \mathrm{K}_{\mathrm{TH}}^{\star}$, is stress ratio dependent and is not accounted for in the modified Forman equation. If the applied $\Delta K$ is less than $\Delta \mathrm{K}_{\mathrm{TH}^{\prime}}^{*}$ then equation (1) is not applicable and no crack growth results. The threshold for each cycle, $\Delta \mathrm{K}_{\mathrm{TH}}^{*}$ was calculated from a read in value of $\Delta K_{T H}$ at $R=0.0$, as defined from constant amplitude data, such that

$$
\Delta \mathrm{K}_{\mathrm{TH}}^{*}=\left(1-\mathrm{R}^{\mathrm{eff}}\right) \Delta \mathrm{K}_{\mathrm{TH}}
$$

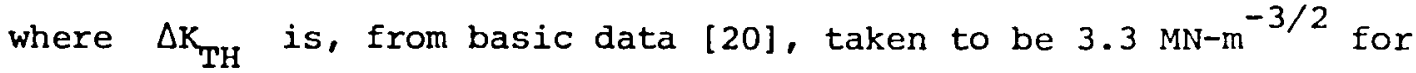
2219-T851 aluminum alloy.

A method for assessing constant amplitude crack growth data as well as an efficient and accurate crack growth accumulation/integration routine for 
the Forman equation have been previously presented by the author in reference 21 and will not be repeated herein.

In summary, then, to calculate an increment of crack growth equation (1) is used. Two situations may exist; $\Delta \mathrm{K}$ is below threshold, and $\mathrm{da} / \mathrm{dN}=0$; or $\Delta \mathrm{K}$ is above threshold, and load interaction effects are taken into account by properly adjusting the effective stress ratio, $R^{\text {eff }}$. Most of the remainder of this paper describes the procedures used to determine the proper values of $R^{\text {eff }}$ to be used in equation (1) during each load cycle. LOAD INTERACTION MODEL

Realistic aircraft loading results in a mixture of high and low stresses associated with varying stress ranges. The influence of any given load cycle on crack growth behavior depends upon the prior load history, thus the term "load interaction" is used to describe these effects. The load interaction model used by the author to predict crack growth under spectrum loading is referred to as the Multi-Parameter Yield Zone (MPYZ) model. The MPYZ is a phenomenological model that is intended to account for such recognized load interactions as retardation caused by previous overloads, acceleration due to current overloads, and underload effects. Retardation results in less crack growth for a given load cycle than would be produced under the same constant amplitude condition. Conversely, acceleration results in more crack growth than would be expected under constant amplitude. The underloads result in a reduction of the retardation effects of the current overload. The MPYZ model began in 1973 [15] as a form of the willenborg retardation model [2]. During 1976, in reference 21, two parameters were added to the Willenborg model. These parameters correspond to ratios of a single 
overload stress intensity to the following applied stress intensity that resulted in (1) no crack growth retardation (parameter A) or (2) complete crack growth retardation (parameter B). Parameter B is very similar to the "shut-off" ratio implemented by Gallagher [16] .

In the present model, load interaction effects are calculated utilizing a residual stress intensity, $K_{R}$, concept. Crack growth retardation and acceleration are accounted for by decreasing or increasing, respectively, the effective stress ratio used in a modified Forman crack growth equation. The $R^{\text {eff }}$ is a function of the residual stress intensity, $K_{R}$, and the currently applied stress intensity. The effective stress range that is used to calculate crack growth remains the same, but the mean of the stress range is altered by $K_{R}$ to account for the appropriate load interaction. The stress ratio corresponding to a load interaction will be designated $R^{\text {eff }}$ and defined as follows:

$$
R^{\text {eff }}=\frac{K_{\min }-K_{R}}{K_{\max }-K_{R}}=\frac{K_{\min }^{e f f}}{K_{\max }^{e f f}}
$$

where $K_{R}$ is the residual stress intensity which will be discussed in the following section. The $k_{R}$ will be positive or negative depending on whether the load interaction produces retardation or acceleration, respectively. The maximum allowable value of $R^{\text {eff }}$ is $R_{\max }$ as defined in equation (2). A simplified flow chart of the MPYZ model in the CGR computer program is presented in figure 2. The three primary phenomenological events of load interaction, i.e., retardation, acceleration, and underload effects, will be addressed in the following sections. 
The amount of crack growth retardation for a given applied cycle depends upon the applied loading as well as the extent of crack growth into the overload plastic zone, as suggested by Willenborg, Engle, and Wood [2].

Gallagher [5] expressed the Willenborg model as

$$
\mathrm{K}_{\mathrm{R}}^{\mathrm{W}}=\mathrm{K}_{\max }^{\mathrm{OL}}\left(1-\frac{\Delta \mathrm{a}}{\mathrm{z}_{\mathrm{OL}}}\right)^{1 / 2}-\mathrm{K}_{\max }
$$

where $K_{R}^{W}$ is the willenborg residual stress intensity factor; $K_{\max }^{O L}$ is the maximum stress intensity for the overload cycle; $\mathrm{K}_{\max }$ is the maximum stress intensity for the current load cycle; $\Delta \mathrm{a}$ is the crack growth increment between the overload cycle and the current cycle as depicted in figure 3. The Willenborg model applies $z_{O L}$ as the plastic zone radius associated with $\mathrm{K}_{\max }^{\mathrm{OL}}$. But in the present MPYZ model, $\mathrm{z}_{\mathrm{OL}}$ is defined as the zone diameter such that

$$
z_{\mathrm{OL}}=\frac{1}{\alpha \pi}\left(\frac{\mathrm{K}_{\max }^{\mathrm{OL}}}{\sigma_{\mathrm{YS}}}\right)^{2}
$$

where

$$
\begin{aligned}
\alpha \quad & \text { plastic zone constraint factor } \\
& =3, \text { plane strain } \\
& =1, \text { plane strain } \\
\sigma_{Y S} & =\text { material yield stress }
\end{aligned}
$$

The plastic zone diameter is used to calculate $\mathrm{K}_{\mathrm{R}}^{\mathrm{W}}$. Mills, Hertzberg, and Roberts [18] have shown that the retardation effects last approximately one plastic zone diameter in A514F steel. Himmelein and Hillberry [11] present 
data that also imply the overload is effective over the plastic zone diameter for 2024-T6 aluminum.

The residual stress intensity, $K_{R^{\prime}}^{W}$ calculated in equation (5) physically represents the difference between the stress intensity required to produce a current plastic zone equal to $\mathrm{z}_{\mathrm{OL}}-\Delta \mathrm{a}$ and the current applied stress intensity, $\mathrm{K}_{\max }$. Retardation occurs when $\mathrm{K}_{\mathrm{R}}^{\mathrm{W}}$ is greater than zero. In such cases the residual stress intensity at the crack tip is greater than that for an equivalent constant amplitude case, so there is less crack growth, i.e.. retardation.

Figure 4 presents a typical aircraft load sequence. Notice that the overload and underload are labeled. The dashed line represents the decay in effective overload stress intensity, $x_{O L}^{e f f}$. The value of $k_{O L}^{e f f}$ decreases with each cycle of crack growth.

Gallagher and Hughes [5] introduced a proportionality factor, $\phi_{R^{\prime}}$ such that

$$
\mathrm{K}_{\mathrm{R}}=\phi_{\mathrm{R}} \mathrm{K}_{\mathrm{R}}^{\mathrm{W}}
$$

The $\phi_{\mathrm{R}}$ term adjusts the amount of retardation according to several material and load history parameters. Notice that the higher the value of $\phi_{R}$ the more the retardation.

The MPYZ load interaction model incorporates

$$
\Phi_{\mathrm{R}}=\left[1.0-\left(\mathrm{K}_{\mathrm{TH}} / \mathrm{K}_{\max }\right)\right] /\left[(\psi-1.0) \times\left(1.0-\mathrm{R}_{\mathrm{L}}\right)\right]
$$


where

$$
\begin{aligned}
& \psi=B / A ; A=\text { the ratio of } K_{\max }^{O L} \text { to } K_{\max } \text { below which no retardation } \\
& \text { takes place (no-retardation ratio) } \\
& B=\text { the ratio of } K_{\max }^{O L} \text { to } K_{\max } \text { above which no crack growth } \\
& \text { is produced (shut-off overload ratio) } \\
& R_{L}=S_{U L} / S_{\text {inax }}^{O L} \text {; ratio if current underload stress to current overload } \\
& \text { stress. } \\
& \text { The }\left[1.0-\left(\mathrm{K}_{\mathrm{TH}}{ }^{\prime} \mathrm{K}_{\max }\right)\right] \text { factor accounts for the threshold level of } \\
& \text { crack growth. The }(\psi-1.0) \text { factor adjusts the retardation between the }
\end{aligned}
$$$$
\text { shut-off overload ratio } B \text { and the no-retardation ratio } A \text { as shown in figure } 5 \text {. }
$$$$
\text { The }\left(1.0-R_{L}\right) \text { expression adjusts the amount of retardation according to }
$$$$
\text { the cyclic range of the spretrum. Similar spectra that differ only in the }
$$$$
\text { minimum underload will hive different overall retardation. This phenomenon }
$$$$
\text { is also observed in crat. "losure [19] where the maximum and minimum stresses }
$$$$
\text { in a spectrum usually set the crack opening stresses therefore controlling }
$$$$
\text { retardation. Notice that a spectrum with negative minimum (i.e., negative }
$$$$
\text { value of } R_{L} \text { ) will produce less retardation for a given ratio of } \mathrm{K}_{\max }^{\mathrm{OL}} / \mathrm{K}_{\max }
$$$$
\text { than a similar loading sequence with a positive minimum stress. }
$$

Parameters A ind $B$ are considered to be material dependent parameters. Ideally, $A$ and $B$ can be determined for a given material by conducting a series of well controlled systematic single overload tests. The ratio of the applied single overload stress to the following stress is varied from test to test in order to ascertain the limiting ratios that (1) produce no overload ef teze (i.e., ratio $=A$ ) and (2) produce no crack growth other th.an that produced by the overload (i.e.; ratio $=B$ ). The types of tests conducted by Probst and Hillberry [12] ares suited to this purpose. If these 
systematic test results are not available for evaluation for a particular material, one has to try various combinations of $A$ and $B$ to predict crack growth and compare the predictions with available test results. Typical values of $A$ and $B$ found in the literature range from 1.0 to 1.5 and 1.8 to 2.5 , respectively, for various materials.

The MPYZ load interaction model uses a simple algorithm to account for multiple overload effects [13]. Simply stated, the more overload cycles one has in succession the greater the retardation effect, i.e., the lower the value of $\mathrm{B}^{\prime}$. Thus this relationship is approximated for 2219-T851 aluminum by

$$
B^{\prime}=\left(\frac{B-2.0}{N_{O L}}\right)+2.0
$$

where

$$
\begin{aligned}
& \mathrm{B}^{\prime}=\text { the value of } \mathrm{B} \text { to be used in equation (8) } \\
& \mathrm{N}_{\mathrm{OL}}=\text { the number of overloads applied in succession }
\end{aligned}
$$

The 2.0 is considered to be a lower bound for $B^{\prime}$ after many overloads for 2219 aluminum alloy

Although the equation is simple, it accounted for the multiple overload effects in reference 17 quite well.

\section{Acceleration}

The crack growth during an overload cycle has been observed to be larger than one might expect from constant amplitude data [14]. This phenomenon is referred to as crack growth acceleration. The acceleration may be attributed to the crack and the resulting crack tip plastic zone growing into an area with less residual stress intensity than that of an equivalent constant 
amplitude case, so that crack growth is less inhibited. For example, imagine that the plastic zone diameter, $z_{a p}$ in figure 2 was caused by a large enough load such that

$$
\Delta \mathrm{a}+\mathrm{z}_{\mathrm{ap}}>\mathrm{z}_{\text {OL }}
$$

This would result in a crack growth acceleration for the applied cycle.

Equation (4) is also utilized for acceleration load interaction. When inequality $(10)$ is true, acceleration occurs, and $K_{R}^{W}$ is a negative value.

The MPYZ load interaction model incorporates an acceleration adjustment term, $\phi_{A}$, for $K_{R}^{W}$ defined as

$$
\phi_{A}=\left(1.0-R_{L}\right)
$$

where the term $\left(1.0-R_{L}\right)$ adjusts the amount of acceleration depending on the ratio of the current underload stress to the overload stress. Thus the residual stress intensity used in equation (4) is defined as

$$
K_{R}=\phi_{A} K_{R}^{W}
$$

for acceleration. Note that $\phi_{A}$ is used to calculate $K_{R}$ when $K_{R}^{W}$ is a negative value. Thus, the effective stress ratio, $R^{\text {eff }}$, will increase.

\section{Underload Effects}

Occasionally in spectrum aircraft-type loading, a rather significant compressive load or a tensile load occurs that is lower than most of the previous minimum loads. This load, $S_{U L}$ ' is defined as an "underload," as depicted in figure 4. An underload has dramatic influence because it can significantly reduce retardation. The author has conducted tests to establish 
the effect on crack growth caused by deleting the compressive stresses from a fighter cycle-by-cycle spectrum. These tests were conducted on 7475-T7651 aluminum in Sump Tank Water (STW) at a maximum spectrum stress of $214 \mathrm{MPa}$ (31 ksi). The fighter spectrum contains relatively few compressive loads for the wing root bending moment spectrum. Those that are present have magnitudes less than 15 percent of the maximum tensile load. As shown in figure 6, the deletion of these few small compressive stresses resulted in a 50 percent increase in life. This substantial increase in crack growth rate cannot be attributed solely to the compressive load excursion increasing the stress range and producing a negative stress ratio. Rather, the negative stresses tend to negate the crack growth retardation caused by previous tensile overloads.

Hillberry and associates [10-12] have conducted several studies into this particular phenomenon. In reference 10 underloads of varying amplitude were applied immediately after an overload to assess the effect of each underload amplitude on the following crack propagation behavior. These data are very useful in modeling the underload phenomenon. Chang and stolpestad [17] also have conducted several simple variable amplitude tests that lend themselves to characterizing the effects of underloads.

In actual aircraft load histories, a significant underload may not immediately follow a large overload. Therefore, in order to generalize the model to realistic spectrum loadings, an effective overload is computed whenever an underload cycle is applied. The effective overload represents the remaining contribution of $\mathrm{K}_{\max }^{\mathrm{OL}}$ before underload application, to simulate the conditions of Hillsberry's data upon.which the following model is based. 
The effective overload is assumed to be the load required to create a plastic zone size of $z_{O L}-\Delta a$ in figure 3. The effective overload stress intensity is therefore equal to $\mathrm{K}_{\mathrm{eff}}^{\mathrm{OL}}$ where

$$
\mathrm{x}_{\mathrm{eff}}^{\mathrm{OL}}=\mathrm{k}_{\max }^{\mathrm{OL}}\left(1-\frac{\Delta \mathrm{a}}{\mathrm{z}_{\mathrm{OL}}}\right)^{1 / 2}
$$

The underload is accounted for by reducing the effective overload stress intensity factor using the ratio

$$
B=\frac{k_{p r}-K_{U L}}{k_{\text {eff }}-K_{U L}}
$$

where $\mathrm{K}_{\mathrm{pr}}, \mathrm{K}_{\mathrm{eff}}^{\mathrm{OL}}$, and $\mathrm{K}_{\mathrm{UL}}$ are shown in figure $4 . \mathrm{K}_{\mathrm{pr}}$ is the minimum value of stress intensity before the overload. Thus a new effective overload stress intensity factor, denoted $\mathrm{K}_{\mathrm{OL}}^{\prime}$ ' is computed and used in accounting for crack growth retardation. The value of this effective overload stress intensity, $\mathrm{K}_{\mathrm{OL}}^{\prime}$, is expressed as

$$
K_{O L}^{\prime}=\frac{K_{e f f}^{O L}}{Z-Y}(z-B)+K_{\max }
$$

where $Z$ is the value of $B$ above which $K_{O L}^{\prime}$ is $K_{\max }$ and $Y$ is the value of $B$ below which $K_{O L}^{\prime}=K_{\text {eff }}^{O L}$. Thus, $Y$ determines when the underload does not reduce the amount of retardation, and $z$ determines when no retardation occurs. The relationship among these variables is indicated in figure 7 .

Notice, in figure 7, that when $\beta<Y$ the underload has no effect on retardation and $\mathrm{K}_{\mathrm{OL}}^{\prime}$ equals $\mathrm{K}_{\text {eff }}^{\mathrm{OL}}$ Likewise, when $B$ is greater 
than $z, x_{\mathrm{OL}}^{\prime}$ equals $\mathrm{k}_{\max }$ so no retardation results. If $B$ is between the values of $Y$ and $z$ the effective overload, $\kappa_{O L}^{e f f}$, is reduced. The relationship between $B$ and $K_{O L}^{\prime}$ depends on the values of $Y$ and $z$ and can be represented by a straight line.

The $Y$ and $Z$ for the particular material must be determined in a similar fashion as that for $i$ and B. Carefully controlled crack growth tests can be run in a systematic manner to completely determine the crack growth load interaction behavior. Tests as conducted in reference 10 are ideal for the determination of $Y$ and $z$.

\section{RESULTS OF SPECTRUI CRACK GROWTH PREDICTIONS}

The crack growth prediction computer program, CGR-LaRC (an updated version of CGR $[15,15])$, vas used to make predictions for the present roundrobin tests. The progran required the usual descriptions of shape and material propertios of the test specimen to be analyzed. In addition the program required the four load interaction parameters $\mathrm{A}, \mathrm{B}, \mathrm{Y}$, and $\mathrm{Z}$ as discussed in the previous section. These parameters, as well as the material data for the 2219-T851 aluminum, are presented in table 1. Notice that $A=1.0$ and $y=0.0$ such that there are essentially only two load interaction paraneters uces to describe 2219-T851 aluminum, $B$ and $Z$. The $B=2.3$ agress vith data presented in reference 12 .

Reference 17 contained many simple single overload tests. The tests were not systematic (i.e., each test conducted at an incrementally different value of overload ratio) but they did cover a wide range of overload ratios, $\mathrm{K} O \mathrm{~L}$

$\frac{\max }{K_{\max }}$. The $A, B, Y$, and $\mathrm{Z}$ terms were selected from the simple overload 
test observations and to provide the best fit of the predicted to the experimental test results for these simple tests.

The round-robin program consisted of 13 tests. Five basic aircraft type spectra were used. Three of the spectra were applied at three different load factors (i.e., different scaling of the stresses) and two spectra were applied at two different load factors. There was only one test per individual spectrum. More details are available in reference 17.

The round-robin specimens contained a through center crack. The secant correction factor was used to calculate the stress intensity factor [23]:

$$
K=\sigma \sqrt{\pi a} \quad \sqrt{\sec \frac{\pi a}{2 b}}
$$

where

$\sigma=$ the remote stress

$a=$ half surface crack length

$\mathbf{b}=$ half specimen width.

Figure 8 is a plot of the predicted lives versus the test lives from the 13 tests in the round-robin effort. The solid line represents exact predictions. The dashed lines are a factor of two high or low. The mean and standard deviations of the ratio of predicted life to test life are 0.97 and 0.24 , respectively. The standard error for the 13 test predictions is

$$
\text { S.E. }=\frac{\sum\left|1-\frac{N_{\text {pred }}}{N_{\text {test }}}\right|}{13}=0.18
$$


Figure 9 presents the predicted and experimental crack growth curves of specimens $M-90, M-91$, and M-92 for comparison. The shape of the predicted crack growth curve is in excellent agreement with that of the experimental.

All of the predictions were within a factor of 1.5 of the test results. In general, all predictions were extremely good with $M-88$ and $M-89$ being the poorest. (See table 2.) Notice in this table that the ratio of the predicted life to the test life is shorter at higher load factors within each spectrum $(81-83,84-86,88-89,90-92,93-94)$. This is attributed to the changes in the constraint at the crack tip. All of the presented predictions assumed plane strain conditions in order to be slightly conservative overall. The higher the stresses the more likely plane stress occurs, especially during a high overload. This definite relationship between applied stress levels and prediction accuracy would suggest the need for a variable constraint factor which would be a function of the ratio for plastic zone diameter to the material thickness.

Table 2 also presents crack growth predictions using no interaction effects, i.e., linear cumulative danage. These predictions are surprisingly good. This indicates that the acceleration and retardation produced by the load interactions nearly negate each other for most of the spectra. Only specimens $M-88$ and $M-89$ had a sufficiently high overload such that retardation dominated the life. Specimens $M-93$ and $M-94$ were dominated by crack growth acceleration as is obvious from the very long life predicted with no load interaction. 
This paper presented a phenomenological load-interaction model developed to predict crack growth propagation under any arbitrary load sequence. The present model is referred to as the Multi-Parameter Yield Zone (MPYZ) Load Interaction Model. Crack growth retardation and acceleration are accounted for by decreasing or increasing, respectively, the effective stress ratio used in a modified Forman's crack growth equation.

The presented MPYZ load interaction model in conjunction with the CGR-LaRC computer routine did a good job of predicting spectrum fatigue crack growth in 2219-T851 aluminum. However, the predictions were not perfect as illustrated by $M-88$ and $M-89$ where too much crack growth retardation was predicted. It is difficult to truly assess the prediction accurately since the validity of individual tests may be suspect due to a lack of replicate tests. Furthermore, many of the spectra were not a true test of a load interaction model since linear cumulative damage models worked well.

The MPYZ model has undergone many refinements during the past 4 years since phenomena such as crack growth acceleration and underload effects have been recognized and investigated. This, indeed, increases the general applicability of this model over those models capable of accounting only for retardation effects. 
REFERENCES

1. Wheeler, O. E., "Spectrum Loading and Crack Growth," J. of Basic Eng.' ASME, Vol. 94, Ser. D, No. 1, March 1972, p. 181.

2. Willenborg, J. D.., Engle, R. M., Jr., and Wood, H. A., "A Crack Growth Retardation Model Using Effective Stress Concept," AFFDL-TM-71-1-FBR, January 1971.

3. Elber, พ., "The Significances of Fatigue Crack Closure," ASTM STP 486, 1961, pp. 230-242.

4. Gray, T. D. and Gallagher, J. P., "Predicting Fatigue Crack Retardation Following a Single Overload Using a Modified Wheeler Model," ASTM STP 590, 1975.

5. Gallagher, J. P. and Hughes, T. F., "Influence of Yield Strength on Overload Affected Fatigue Crack Growth Behavior in 4340 steel," AFFDL-TR-74-27, July 1974.

6. Bell, P. D. and Creager, M., "Crack Growth Analysis for Arbitrary Spectrum Loading," AFFDL-TR-74-129, October 1974.

7. Gallagher, J. P., "A Generalized Development of the Yield Zone Models," AFFDL-TM-FBR-74-28, January 1974.

8. Hagemeyer, J. W., "Overload Induced Retardation of Fatigue Cracks in Several Aluminum and Titanium Alloys," General Dynamics ERR-FW-1779, Dec. 1976.

9. Johnson, พ. S. and Hagemeyer, J. พ., "Yield Stress Consideration for Selecting Materials Subjected to Spectrum Loads," International J. of Fracture, Vol. 13, No. 4, August 1977. 
10. Hillberry, B. M., Alzos, W. X., and Skat, A. C., "The Fatigue Crack Propagation Delay Behavior in 2024-T3 Aluminum Alloy Due to Single Overload/Underload Sequences," Air Force Flight Dynamics Lab Report, AFFDL-TR-75-96, August 1975.

11. Himmelein, M. K. and Hillberry, B. M., "The Effect of Stress Ratio and Overload Ratio on Fatigue Crack Delay and Arrest Behavior Due to Single Peak Overloads," ASTM STP 590, 1975.

12. Probst, E. P. and Hillberry, B. M., "Fatigue Crack Delay and Arrest Due to Single Peak Tensile Overloads," AIAA Journal, 12:3, March 1974, pp. $330-335$.

13. Trebules, V. W., Roberts, R., and Hertzberg, R. W., "Effects of Multiple Overloads on Fatigue Crack Propagation in 2024-T3 Aluminum Alloy," ASTM STP 536, 1973, pp. 115-146.

14. Hall, L. R., Shah, R. C., and Engstrom, W. L., "Fracture and Fatigue Crack Growth Behavior of Surface Flaws and Flaws Originating at Fastener Holes," AFFDL-TR-74-47, May 1974.

15. Johnson, W. S., "CGR, An Improved Computerized Model to Predict Fatigue Crack Growth Under Spectrum Loading," NSRDC Report 4577, Jan. 1975. 16. Johnson, W. S. and Spamer, T., "A Users Guide to CGR-GD, A Computerized Crack Growth Predicting Program," General Dynamics Report F25-241, Nov. 1976 .

17. Chang, J. B. and Stolpestad, J. H., "Improved Methods for Predicting Spectrum Loading Effects - Phase I Report," Vol. II - Test Data, Air Force Flight Dynamics Lab Report, AFFDL-TR-79-3036, March 1978. 
18. Mills, W. J., Hertzberg, R. W., and Roberts, R., "Load Interaction Effects on Fatigue Crack Growth in A514F Steel Alloy," Cyclic Stress-Strain and Plastic Deformation Aspects of Fatigue Crack Growth, ASTM STP 637, American Society of Testing and Materials, 1977, pp. 192-208.

19. Newman, J. C., Jr., "Prediction of Fatigue Crack Growth Under Spectrum Loading Using a Crack Closure Model," Methods and Models for Predicting Fatigue Crack Growth Under Random Loading, ASTM STP , 1981, pp.

20. Hudak, S. J., Jr., Saxena, A., Bucci, R. J., and Malcolm, R. C., "Development of Standard Methods of Testing and Analyzing Fatigue Crack Growth Rate Data," AFML-TR-78-40, May 1978.

21. Johnson, W. S., "Prediction of Constant Amplitude Fatigue Crack Propagation in Surface Flaws," ASTM STP 687, American Society for Testing and Materials, 1979, pp. 143-155.

22. Johnson, W. S., Rister, W. C., and Spamer, T., "Spectrum Crack Growth in Adhesively Bonded Structure," J. of Eng. Material and Tech., ASME Trans. Vol. 100, No. 1, Jan. 1978, pp. 57-63.

23. Tada, H., Paris, P. C., and Irwin, G. R., "The Stress Analysis of Cracks Handbook," Del Research Corp., 1973.

24. Forman, R. G., Kearney, V. E., and Engle, R. M., "Numerical Analysis of Crack Propagation in Cyclic-Loaded Structures," J. of Basic Eng., Trans. of ASME, Series D, Vol. 89, No. 3, Sept. 1967, pp. 459-464. 
TABLE 1.- MATERIAI PROPERTIES FOR 2219-T85I USED FOR PREDICTION

\begin{tabular}{|c|c|}
\hline CRACK GROWTH CONSTANTS & MPYZ MODEL PARAMETERS \\
\hline $\begin{aligned} \mathrm{c} & =4.626 \times 10^{-9} \\
\mathrm{n} & =3.171 \\
\mathrm{~K}_{\mathrm{c}} & =88 \mathrm{MN}-\mathrm{m}^{-3 / 2} \\
\Delta \mathrm{K}_{\mathrm{TH}} & =3.3 \mathrm{MN} / \mathrm{m}^{-3 / 2} \\
\text { Yield stress } & =345 \mathrm{MPa} \\
\text { Ultimate stress } & =448 \mathrm{MPa}\end{aligned}$ & $\begin{array}{l}A=1.0 \\
B=2.3 \\
Y=0.0 \\
Z=0.5\end{array}$ \\
\hline
\end{tabular}


TABLE 2.- CRACK LIFE PREDICTION RESULTS

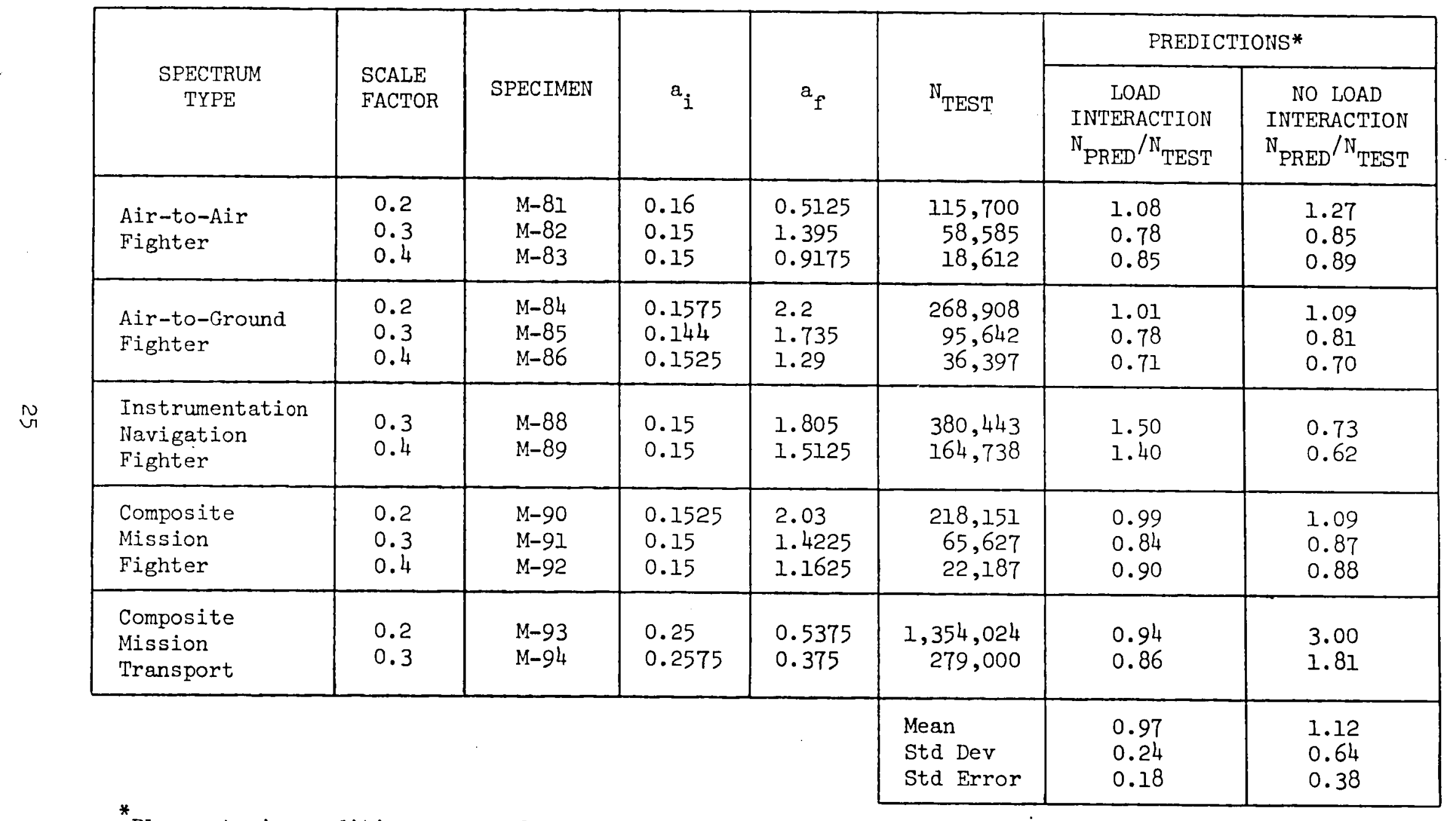

Plane strain conditions assumed. 


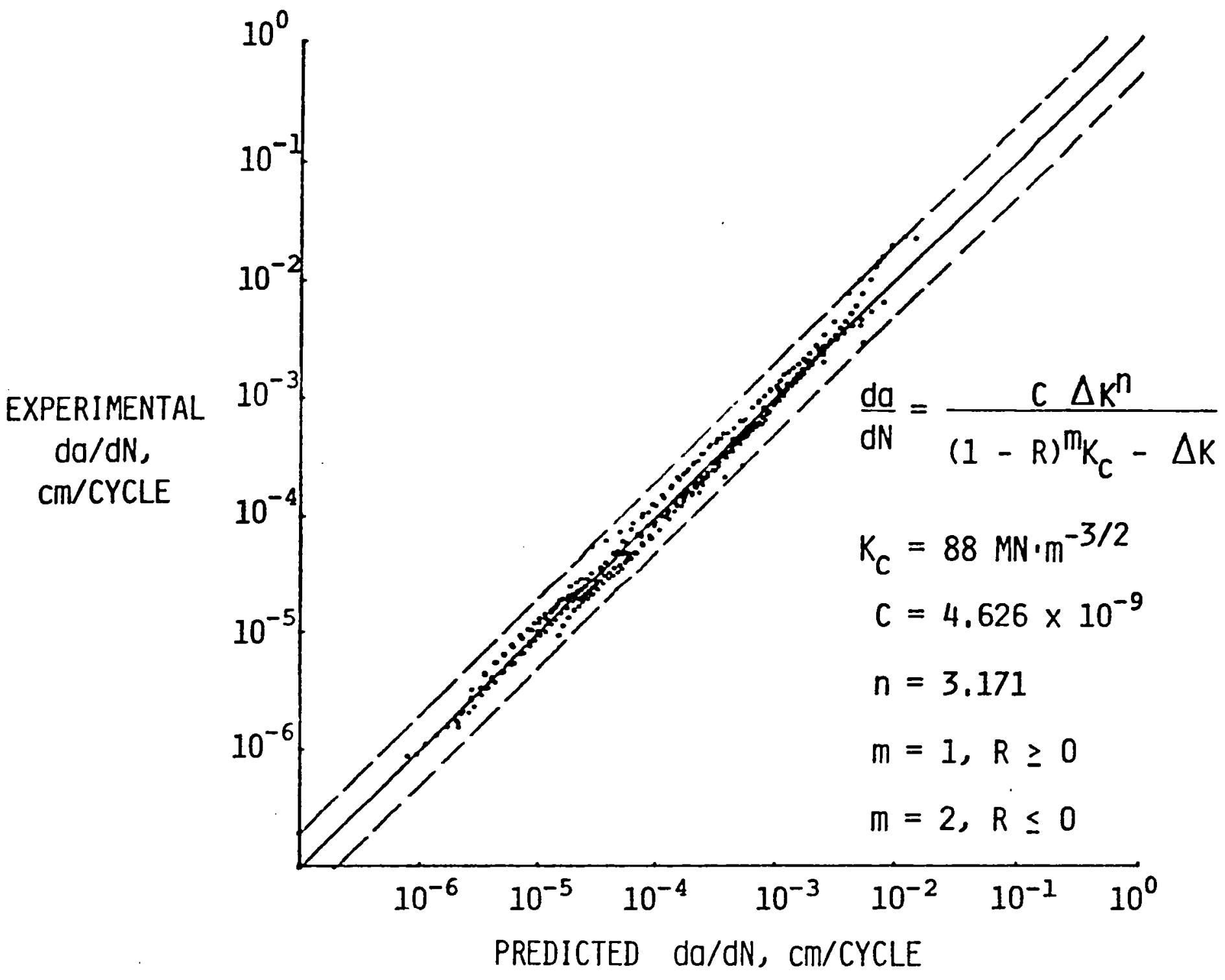

Figure 1,- Constant amplitude cráck growth rate correlation, 
(1)

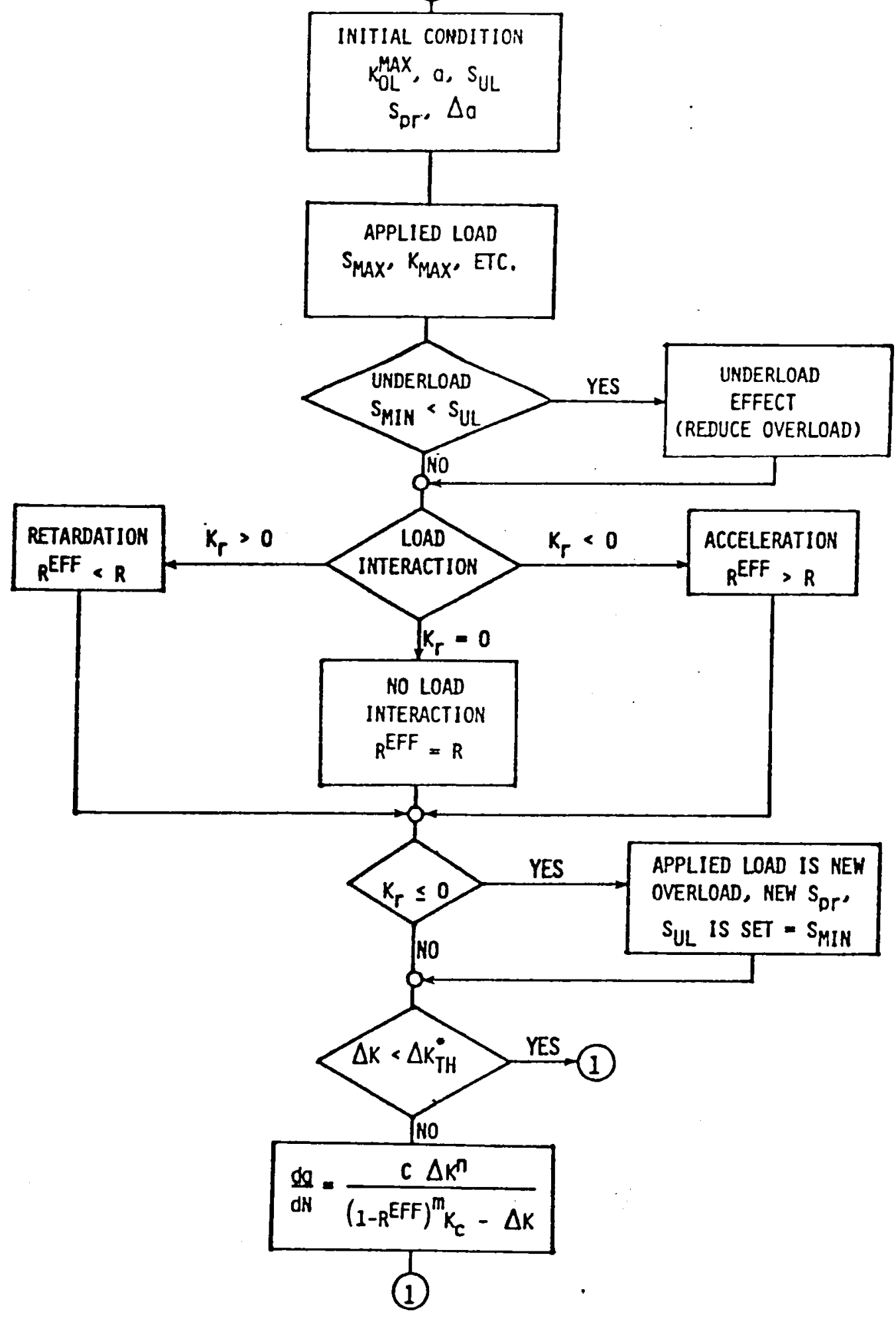

Figure 2,- Flow chart of the MPYZ load interaction model, 


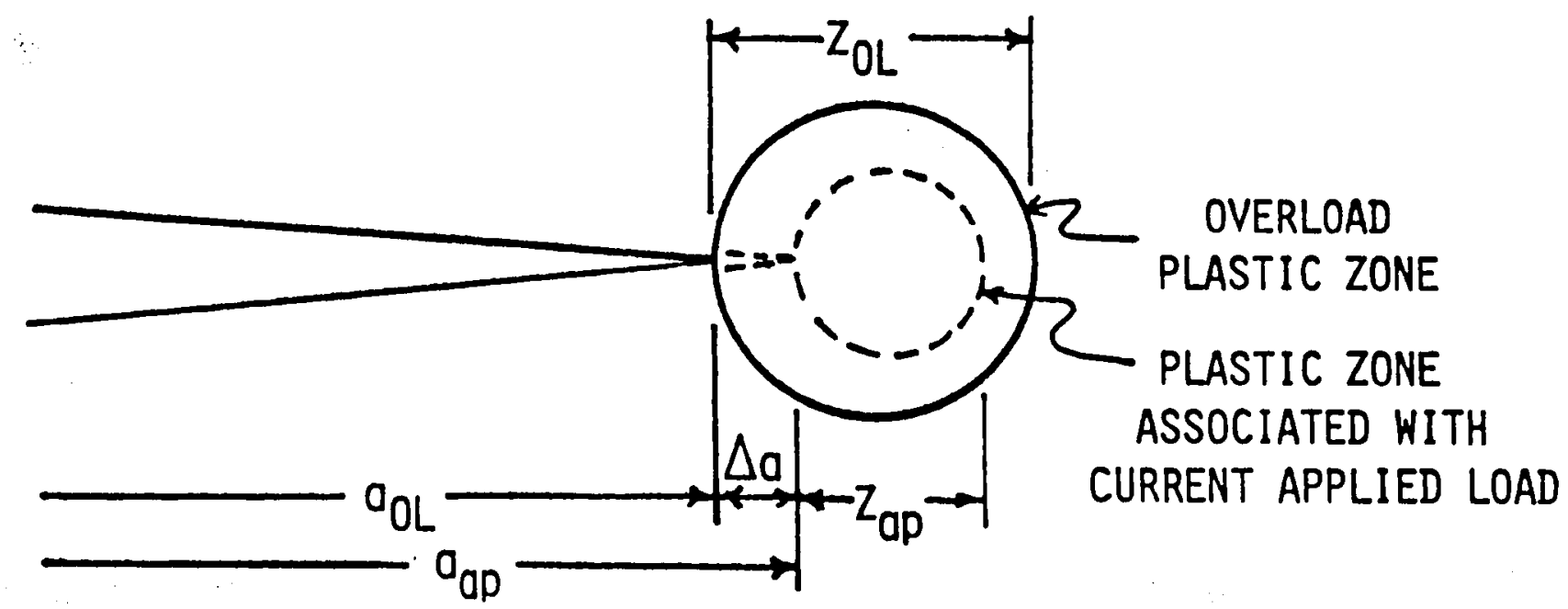

Flgure 3,- Plastic zones at crack tip. 


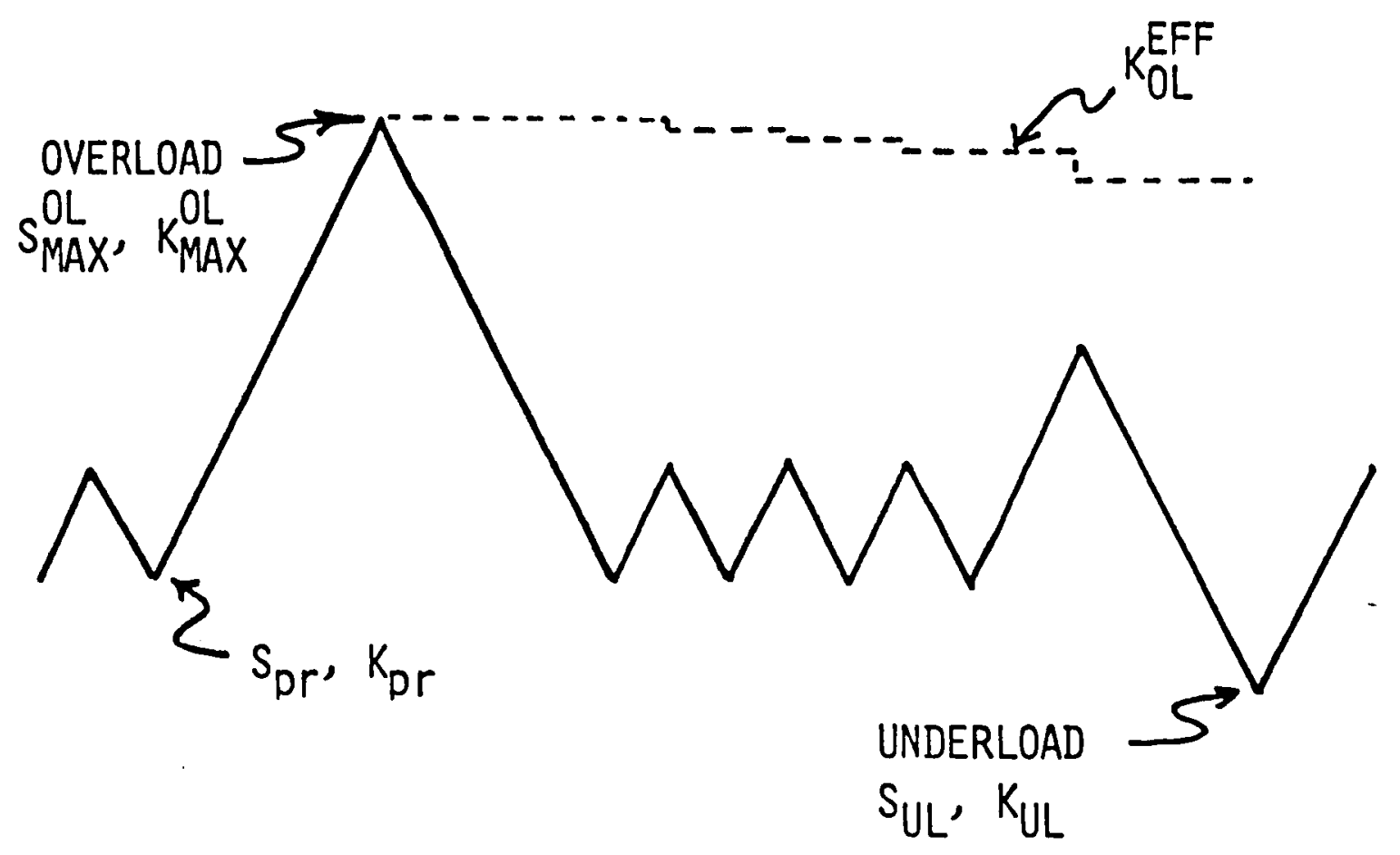

Fiqure 4.- Example spectrum sequence. 


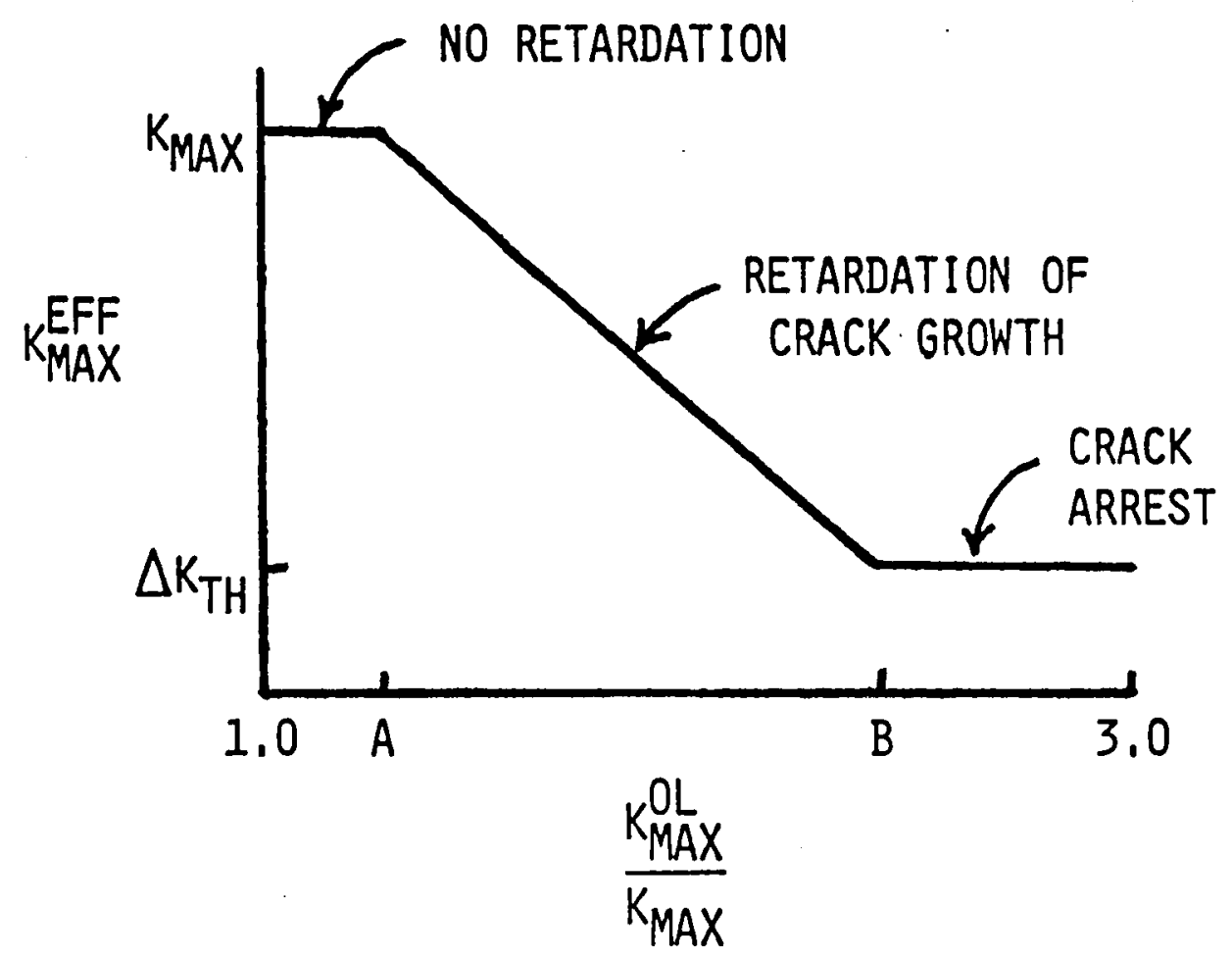

Figure 5,- Schematic of retardation in the MPYZ load interaction model. 


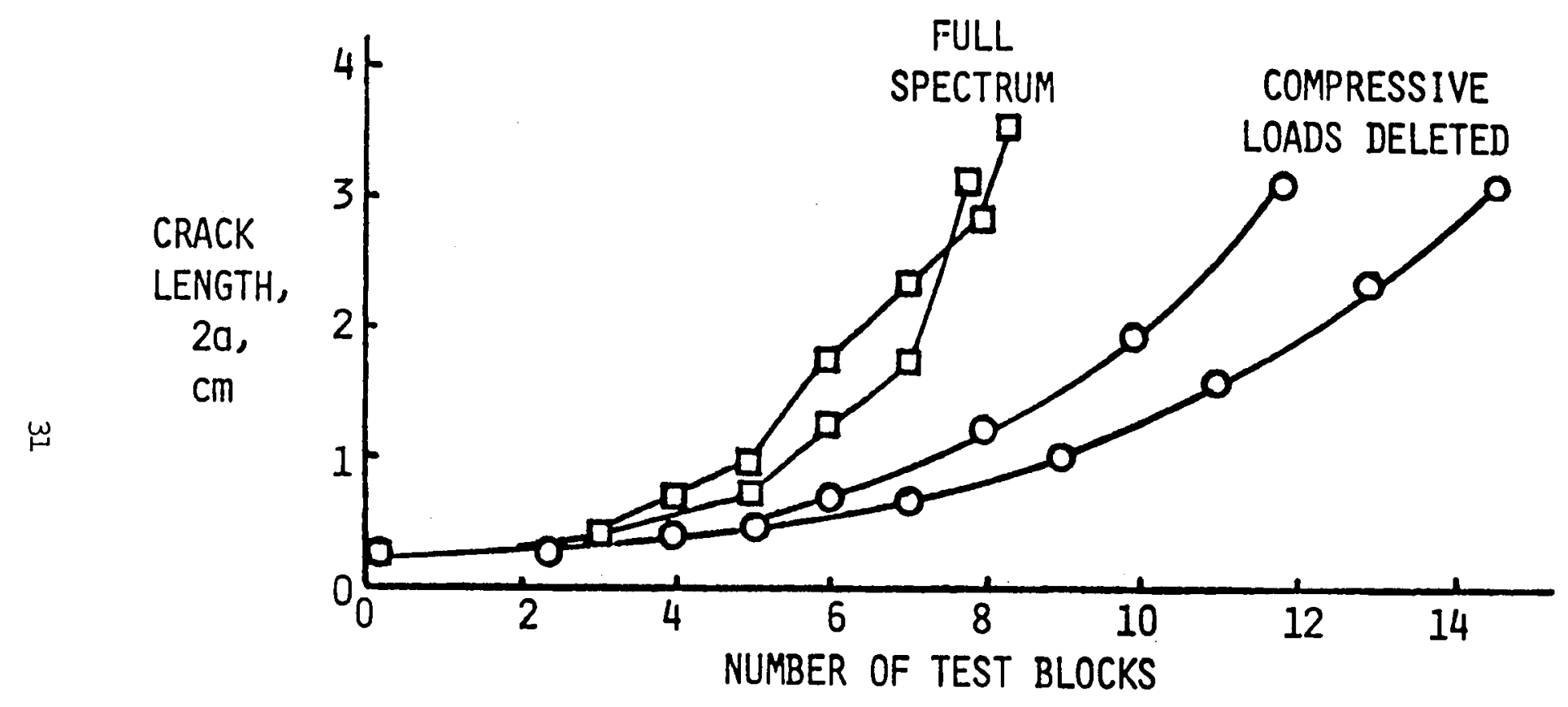

Figure 6.- The effect on crack growth of truncating neadive loads from a flight-by-fl laht fiahter spectrum. 


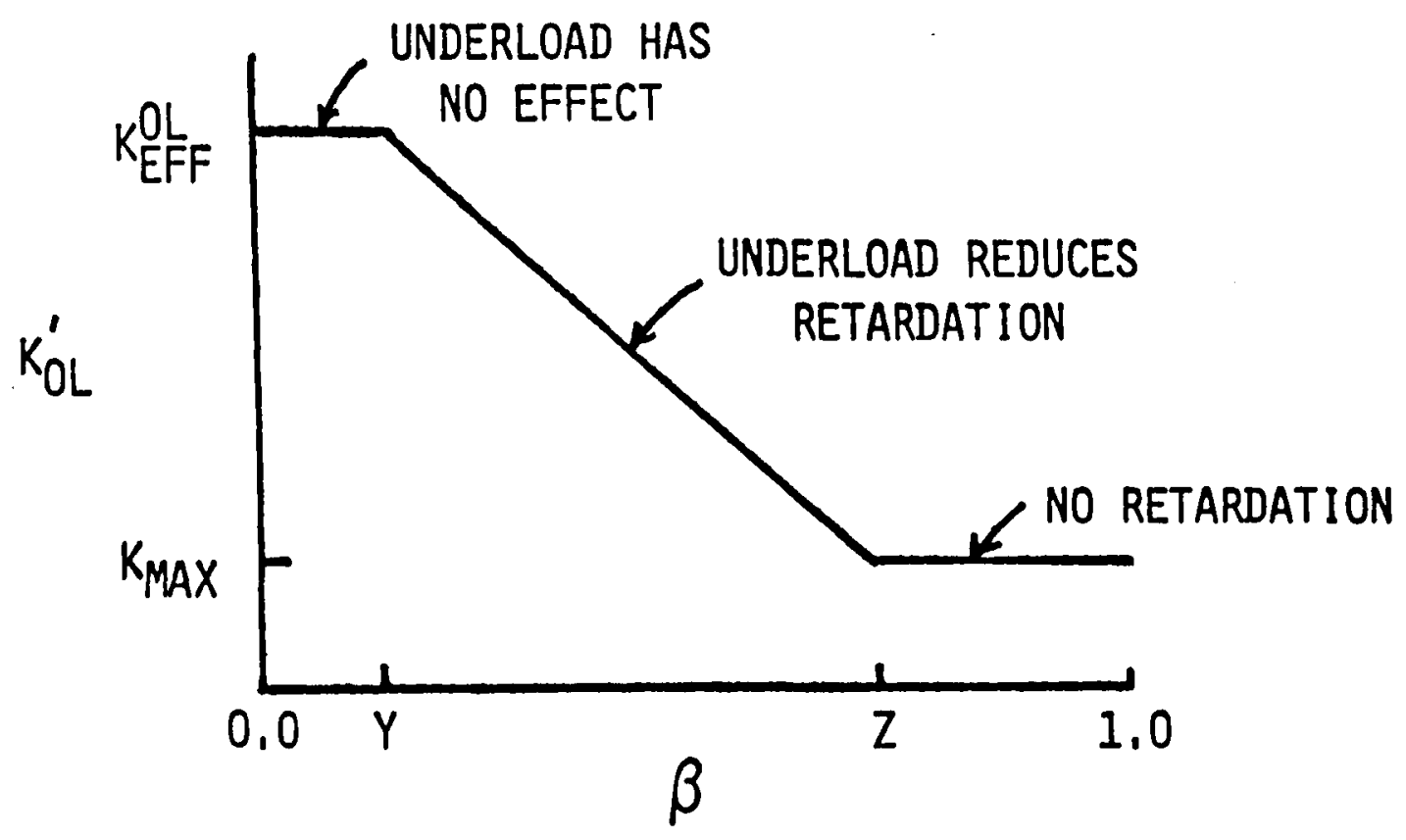

Figure 7.- Schematic of underload effects in the MPYZ load interaction model. 


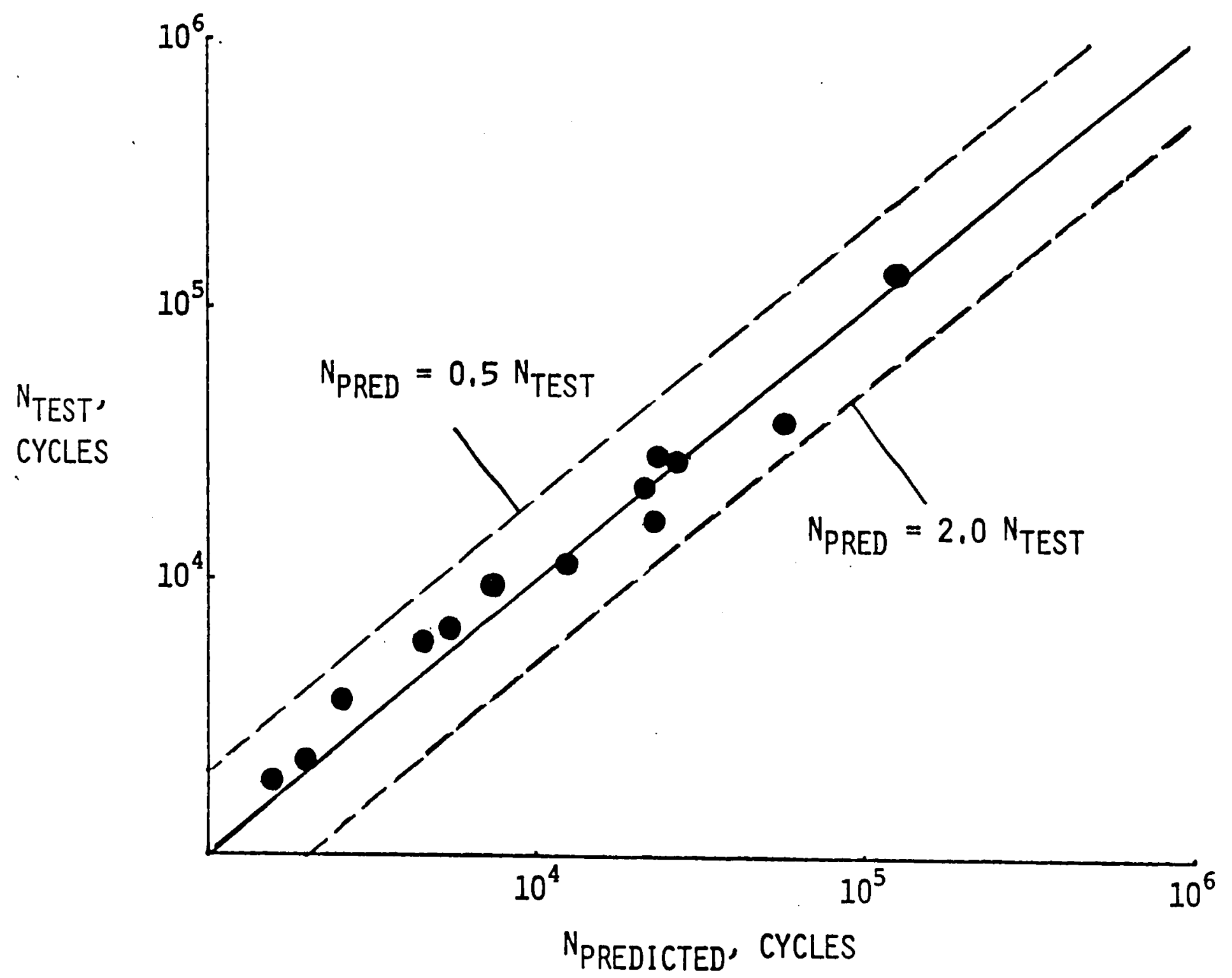

Figure 8, - Correlation of predicted $11 \mathrm{fe}, \mathrm{N}_{\text {PRED }}$, to test $11 \mathrm{fe}, \mathrm{N}_{\text {TEST }}$. 


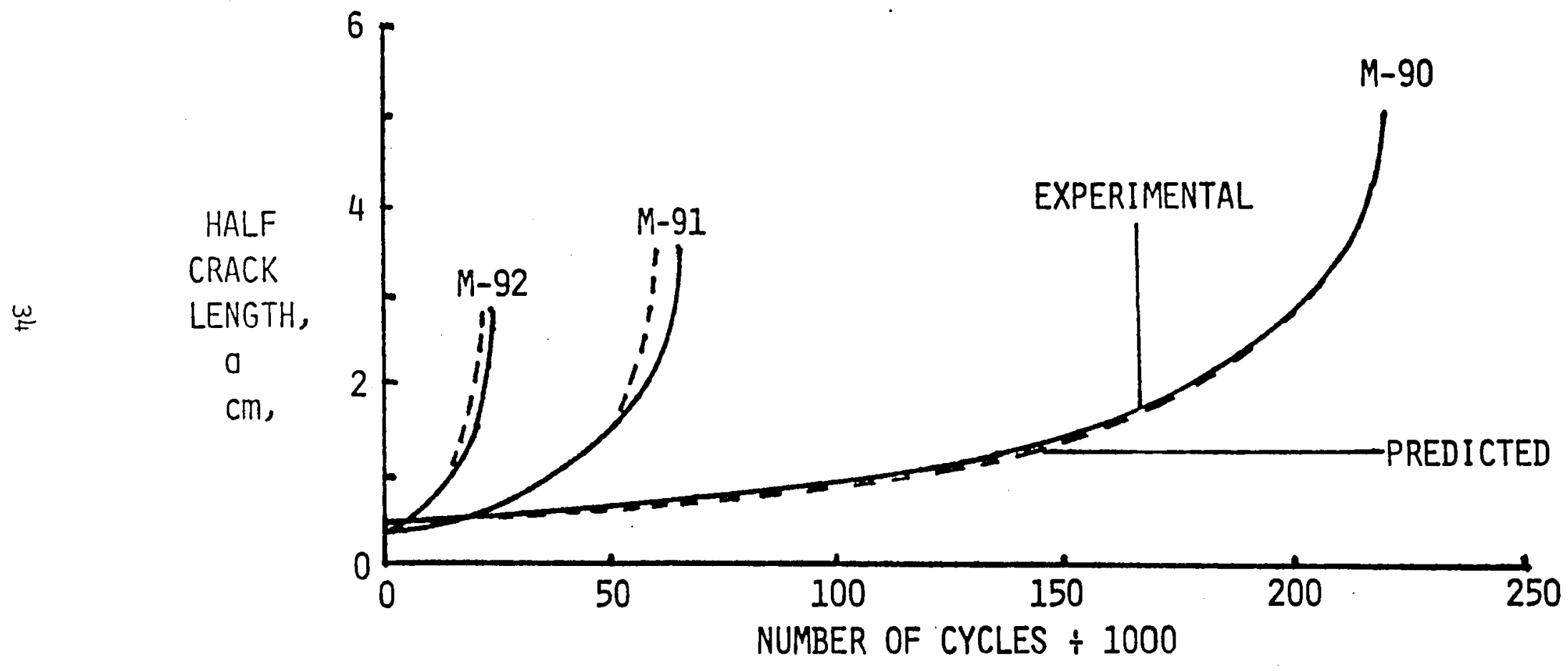

Figure 9.- Example crack growth predictions for the fighter composite mission spectra. 


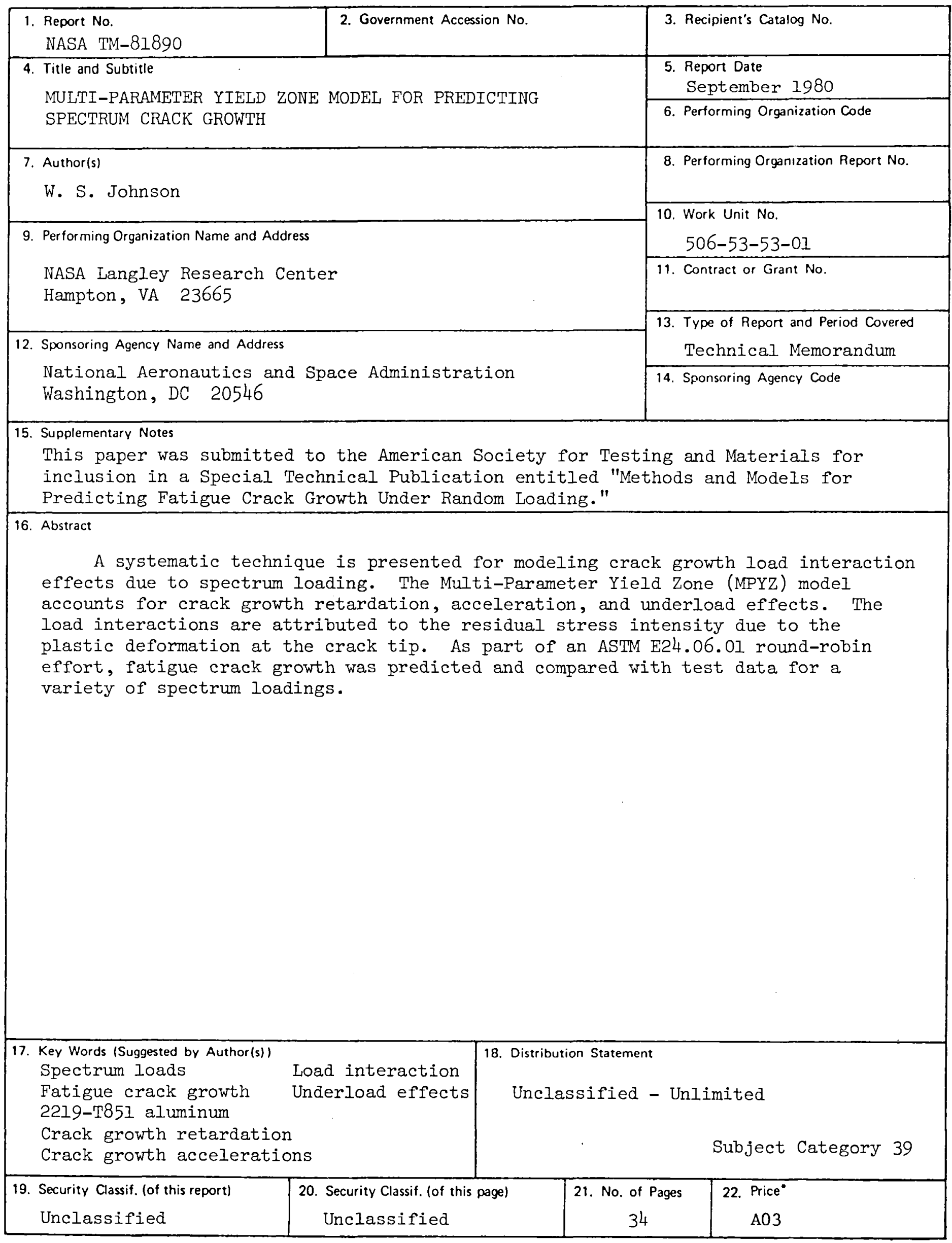

* For sale by the National Technical Information Service, Springfield, Virginia 22161 


-




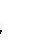

